\title{
Features and Recursive Structure in Phonology ${ }^{*}$
}

\author{
Kuniya Nasukawa \\ Tohoku Gakuin University
}

\section{Introduction}

In theories of phonological representation which employ elements as melodic primes and licensing/government as a device for controlling dependency relations between phonological units (Kaye, Lowenstamm \& Vergnaud 1990; Kaye 1990, 1992; Harris 1990, 1994, 1997; Charette 1991; Scheer 2004; Nasukawa 2004, 2005, 2011, Botma, Kula \& Nasukawa and others), not only features (or elements) but also the syllable nucleus is phonetically interpretable. A nucleus may be phonetically realized even it is melodically empty - that is, if it has no features. An empty nucleus is silent when the appropriate conditions are met (e.g. when it is prosodically licensed as a result of being properly governed: Kaye 1990, Harris 1994, Nasukawa 2005), but otherwise it must be phonetically realized. A nucleus without any melodic material is typically pronounced as a central vowel of some kind, the precise quality of which is determined on a language-specific basis (Harris 1994: 109; Nasukawa 2005: 79). In English, for example, this vowel is a mid central vowel a (schwa), in Yoruba and Cilungu $i$ and in Japanese $u$. According to this approach, these vowels are seen as providing an acoustic baseline onto which melodic primes are superimposed. Cross-linguistically, this baseline tends to have a central quality such as $\partial, \dot{i}$, or $u$.

It is generally assumed that the choice of central vowel is parametrically controlled, and thus varies between languages in an unpredictable way. So far, no attempt has been made to explain why these vowels (rather than non-central vowels, for example) serve as the realization of a featureless nucleus.

This paper attempts to account for this parametric choice in a non-arbitrary way by proposing that the nucleus itself is one of the three vowel elements $|\mathrm{A}|,|\mathrm{I}|$ and $|\mathrm{U}|$. These elements belong to a small set of monovalent, independently interpretable primes which function as the building blocks of melodic structure. It is proposed that, for a given language, one of these vowel elements determines the quality of the 'featureless' nucleus: in its acoustically weak form, $|\mathrm{A}|$ is phonetically realized as $\partial$ in English, $|\mathrm{I}|$ as $\dot{i}$ in Cilungu and $|\mathrm{U}|$ as $u$ in Japanese. Accordingly, I claim that $|\mathrm{A}|,|\mathrm{I}|$ and $|\mathrm{U}|$ are the head of a nuclear expression in English, Cilungu and Japanese, respectively. This helps to explain why the central vowel is always one of only three possibilities, rather than five or six.

In addition, this paper shows that elements can be freely concatenated to create melodic compounds. Take, for example, an expression which combines $|\mathrm{I}|$ and $|\mathrm{A}|$. If it is labeled as one belonging to the $|\mathrm{I}|$ set then it is phonetically interpreted as the mid front vowel $e$, whereas if it belongs to the $|\mathrm{A}|$ set it has the interpretation $\varepsilon$. Furthermore, these sets can be dominated by another set of the same kind: the set in which $|\mathrm{I}|(|\mathrm{I}||\mathrm{A}|)$ is dominated by $|\mathrm{I}|(|\mathrm{I}||\mathrm{A}|)$ is interpreted as a long vowel ee. The phonetic value of an element compound (phrase) is thus determined by the specific elements it contains and also the head-dependency relations (labeling) between those elements.

In this paper, I extend this concatenation-based mechanism of melodic structure to levels above the segment. In so doing, I will show that this approach ultimately eliminates the need for constituents such as segment, onset, nucleus, rhyme, syllable, and foot, all of which are generally assumed to be required below the intra-morphemic level. This leads to the proposal that elements, and not prosodic constituents, are the only variables of structural operations. This approach reinterprets the notion of minimalism in phonology

\footnotetext{
* An earlier version of this chapter was presented at Phonology 2013 held at the University of Massachusetts, Amherst. I thank paticipants at the conference for their constructive comments. I am also grateful to Phillip Backley, Noam Chomsky, Michael Kenstowicz, and Marc van Oostendorp for discussion and corrections of earlier versions of this chapter. This research was partially supported by a Grant-in-Aid for Scientific Research (B) from Japan Society for the Promotion of Science, Grant No 22320090.
}

(C) 2014 Kuniya Nasukawa

Proceedings of Phonology 2013

Completed January 2, 2014 
by opposing the string-based flat structure pursued by Scheer (2004), Neeleman \& van de Koot (2006), Samuels (2009) and others. Furthermore, within the framework developed by Hauser, Chomsky \& Fitch (2002), the application of this recursive type of element-based structure at the intra-morphemic level suggests that phonology may belong in FLN rather than FLB, if it is maintained that the existence of recursive structure is a prerequisite for being placed in FLN. ${ }^{1}$

The structure of this paper is as follows. In section 2, I introduce the phonological features employed in this paper and discuss the existence of recursive structure in intra-morphemic phonological structure. Then in section 3 I motivate the need for empty nuclei, and explain how they are phonetically interpreted in the frameworks of Dependency/Government Phonology and Element Theory. I continue in section 4 by arguing that the nucleus itself is one of the three vowel elements $|\mathrm{A}|,|\mathrm{I}|$ and $|\mathrm{U}|$, then in section 5 show the need for recursion in intra-morphemic phonology using an Element-based model of concatenation. Some concluding remarks are given in section 6 .

\section{Monovalent features: elements}

A version of Element-based feature theory developed by Nasukawa (2012) regards features as the units which play a central role in building phonological structure. In this model, unlike Distinctive Feature Theory, but like most recent models based on Element Theory (Nasukawa \& Backley 2008; Backley \& Nasukawa 2009, 2010; Backley 2011), phonological features (called elements) are monovalent and therefore express privative oppositions. Each one is also fully interpretable on its own, and as such, does not require any support from other elements. This implies that there is neither template-like feature organization nor any universally-fixed matrix of features.

Like most types of features, elements are strictly phonological in nature and are viewed as mental or internal objects since they emerge through the observation of phonological phenomena and form the basis of lexical contrasts. However, a crucial difference between elements and SPE-type distinctive features is their reference to the external world. On the other hand, in accordance with most of the views influenced by SPE, the phonetic exponence of features primarily concerns speech production rather than perception: most segments are described by features (e.g. $[ \pm$ high], $[ \pm$ back], $[ \pm$ anterior]) which refer to articulation. On the other hand, For the reasons discussed in Harris \& Lindsey (2000) and Nasukawa \& Backley (2008), element-based theories reject the speaker-oriented (production-based) view in favor of an alternative perspective in which features refer to attributes of the acoustic signal: that is, the phonetic exponence of elements stands in the hearer-oriented (perception-based) view in line with work of Jakobson (Jakobson, Fant \& Halle 1952, Jakobson \& Halle 1956). Support for the perception-based approach is firstly attributed to language acquisition, in which speech perception is an indispensable stage on the acquisition path: it is generally assumed that infants begin to build mental representations for their native lexicon primarily on the basis of perceiving adult inputs. Furthermore the hearer-oriented approach to features is able to capture important phonological generalizations that cannot be expressed by employing articulatory features, such as the close association between labials and velars: they are linked in acoustic terms by a similar 'dark' spectral pattern (Backley \& Nasukawa 2009, cf. the feature [grave] in labials and velars which indicates a concentration of acoustic energy at the lower end of the spectrum, as discussed in Jakobson \& Halle (1956)).

In an element-based theory which adopts a perception-based view of the phonetic exponence of primes (Nasukawa \& Backley 2008, Backley 2011), melodic structure is described by using the six monovalent elements |A I U ? H N|, which are assumed to be active in all natural languages. The elements are listed below, along with their principal phonetic properties.

\footnotetext{
${ }^{1}$ Based on the working hypothesis called Structural Analogy, van der Hulst (2010) also assumes that recursion exists at intra-morphemic levels of phonological organization such as syllable and foot in the framework of Dependency/Government Phonology. He interprets codas as 'syllables within syllables' and feet as 'syllables containing syllables'.
} 
(1)

$\begin{gathered}\text { Elements } \\ \text { label }\end{gathered}$
$|\mathrm{A}|$ 'mAss'
$|\mathrm{I}|$ 'dIp'
$|\mathrm{U}|$ 'rUmp'
$|\mathrm{P}|$ 'edge'
$|\mathrm{H}|$ 'noise'
$|\mathrm{N}|$ 'murmur'

manifestation

as a consonant

uvular, pharyngeal POA

dental, palatal POA

labial, velar POA

oral or glottal occlusion

aspiration, voicelessness

nasality, obstruent voicing

\author{
manifestation \\ as a vowel \\ non-high vowels \\ front vowels \\ rounded vowels \\ creaky voice (laryngealized vowels) \\ high tone \\ nasality, low tone
}

The first three elements $|\mathrm{A} I \mathrm{U}|$ are often grouped together as so-called resonance elements; they are typically associated with vocalicness and prosodic phenomena such as pitch and intonational patterns. The remaining three elements $\mid$ ? $\mathrm{H} \mathrm{N} \mid$ are relevant to non-resonance phenomena such as occlusion, aperiodicity and laryngeal-source effects. In traditional terms, $|\mathrm{A} \mathrm{I} \mathrm{U}|$ tend to be associated with vocalic characteristics and $\mid$ P $\mathrm{H} \mathrm{N} \mid$ with consonantal characteristics. Only the vocalic group $|\mathrm{A} \mathrm{I} \mathrm{U}|$ is directly relevant to the following discussion.

The terms shown in quotation marks on the right of the elements in (2) are the names of their acoustic patterns found in their phonetic exponences. As examples, the spectral shapes and schematic filter response curves of $a, i$ and $u$, which are phonetic manifestations of $|\mathrm{A}|,|\mathrm{I}|$ and $|\mathrm{U}|$ respectively, are illustrated below.

Typical acoustic exponence of elements (Harris 2005: 126, cf. Harris \& Lindsey 2000)

\section{Elements Spectral shapes}

a. $|\mathrm{A}|$ 'mAss': mass of energy located in the center of the vowel spectrum, with troughs at top and bottom

b. $\quad|\mathrm{I}|$ 'dIp': energy distributed to the top and bottom of the vowel spectrum, with a trough in between

c. $|\mathrm{U}|$ 'rUmp': marked skewing of energy to the lower half of the vowel spectrum
Schematic filter response (y-axis=amplitude, $\mathrm{x}$-axis=frequency)

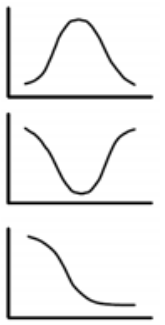

Regarding the pattern 'mAss' in (2a), there exists a concentration of energy (the convergence of F1 and F2) in the center of the spectrum relevant to vowel quality, with troughs at the top and bottom. With respect to the spectral pattern 'dIp' in (2b), it shows energy which is distributed both to the top (the convergence of F2 and F3) and the bottom (the convergence of F0 and F1) of the vowel spectrum, with a trough in between. As for the 'rUmp' pattern in (2c), it exhibits a marked skewing of energy to the lower half of the vowel spectrum (the convergence of F1 and F2).

Spectral patterns similar to those above are also observed in consonants, typically glides. As discussed in Nasukawa \& Backley (2008), Backley \& Nasukawa (2009, 2010) and Backley (2011: 65-67), for example, the 'dIp' pattern (and a high F2) is identified in palatals (typically the palatal glide $j$ ) and coronals, and the 'rUmp' pattern in labials (typically the labial glide $w$ ) and velars (cf. Jakobson, Fant \& Halle 1952). Accordingly, as shown in (1), the 'dIp'-class unites front vowels, palatals and coronals while the 'rUmp'class unites rounded vowels, labials and velars. In other words, with respect to both consonant and vowel segments, all 'dIp'-class segments contain $|\mathrm{I}|$ while $|\mathrm{U}|$ is involved in all 'rUmp'-class segments.

The simplex spectral patterns for the corner vowels $a, i, u$ may combine with each other, resulting in complex spectral patterns. For example, the front mid vowel $e$ is a combination of the 'mAss' and 'dIp' patterns: as illustrated in (3a), there is an energy gap between F1 and F2 although it is closer than in the 'dIp' profile, and there is also a concentration of energy in the central region although there is a slight energy gap between F1 and F2 which is not found in the 'mAss' pattern. The back mid vowel o, on the other hand, is viewed as a combination of the 'mAss' and 'rUmp' patterns: (3b) exhibits a marked skewing of energy towards the lower end of the vowel spectrum even though the peak energy is found at a point above the bottom of the vowel spectrum, which allows us to identify a trough-like shape as found in the 'mAss' pattern. 
(3)
Typical acoustic exponence of elements (Harris 2005: 127)
Elements Complex spectral shapes Schematic filter response
a. $\quad e \quad|\mathrm{~A}|$ and $|\mathrm{I}|:$ 'mAss' + 'dIp'
b. $\quad o \quad|\mathrm{~A}|$ and $|\mathrm{U}|:$ 'mAss' + 'rUmp'

\begin{abstract}
The simplex elements $|\mathrm{A}|,|\mathrm{I}|,|\mathrm{U}|$ and the complex expressions $|\mathrm{A} I|$ and $|\mathrm{A} U|$ are employed in five-vowel systems which typically contain only two mid vowels ( $e$ and $o$ ). When the element-based theory is used to represent languages which, for example, have more than two contrastive mid vowels, it calls upon an asymmetric relation between features. The asymmetry can be observed in relations between the spectral profiles of the two components. Examples include the pairs $e-\varepsilon$ and $o-\supset$ in Italian. As seen in (4a), the energy gap between F1 and F2 in e is wider than that in $\varepsilon(4 \mathrm{~b})$, which implies that the 'dIp' pattern is stronger or more prominent than the ' $m$ Ass' pattern in $\varepsilon$. The same relation between melodic components is identified in the spectral profile of $\supset$ in (4b): the 'mAss' pattern is stronger or more prominent than the 'rUmp' pattern, in comparison with $o$ in $(4 \mathrm{c})$.
\end{abstract}

$$
\begin{aligned}
& \text { Complex vowel expressions } \\
& \text { Elements Complex spectral shapes Schematic filter response } \\
& \begin{array}{llll}
\text { a. } & e & |\mathrm{~A}| \text { and }|\mathrm{I}|: & \text { 'mAss' < 'dIp' } \\
\text { b. } & \varepsilon & |\mathrm{A}| \text { and }|\mathrm{I}|: & \text { 'mAss'> 'dIp' } \\
\text { c. } & o & |\mathrm{~A}| \text { and }|\mathrm{U}|: & \text { 'mAss' < 'rUmp' } \\
\text { d. } & \supset & |\mathrm{A}| \text { and }|\mathrm{U}|: & \text { 'mAss'> 'rUmp' }
\end{array}
\end{aligned}
$$$$
\text { (y-axis=amplitude, } \mathrm{x} \text {-axis }=\text { frequency) }
$$
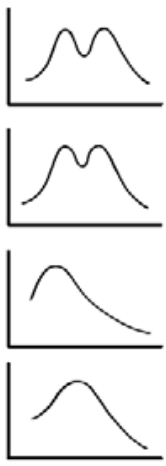

Below it will be argued that it is the elements $|\mathrm{A} I \mathrm{U}|$, rather than syllable nuclei, which are structurally basic and which play a central role in building phonological structure.

\title{
3 Empty nucleus and its phonetic realization
}

In theories of phonological representation which employ elements as melodic primes and licensing/government as a device for controlling dependency relations between phonological units (Kaye, Lowenstamm \& Vergnaud 1990; Kaye 1990, 1992; Harris 1990, 1994, 1997; Charette 1991; Scheer 2004; Nasukawa 2004, 2005, 2011, and others), not only features (or elements) but also the nucleus is phonetically interpretable. This is attributed to the theoretical mechanism that allows a nucleus to be melodically empty: a nucleus can stand alone even if it has no features. The nucleus is phonetically silent when the appropriate condition is met (e.g. when it is prosodically licensed by being properly governed: Kaye 1990, Harris 1994, Nasukawa 2005). Otherwise, it must be phonetically realized. Normally a nucleus without any melodic material manifests itself phonetically as the language-specific central vowel of the system in question (Harris 1994: 109; Nasukawa 2005: 79). In English, for example, this vowel is a mid central vowel a (schwa), in Yoruba and Cilungu $i$, and in Japanese $u$. In the theory, these vowels are considered to be a baseline onto which melodic primes are superimposed. 
A typical context where a melodically empty nucleus is allowed to appear is domain-final position. In the theories employing elements and the notions of licensing and government, the minimal prosodic domain is the onset-nucleus (CV) sequence, which means that morphemes never end with a non-nuclear position (C): morphemes are universally assumed to end with a nucleus (V). In English, for example, the representation of the word $p v$ ' 'push' contains an empty nucleus word-finally, as in (5)

(5) $p v \int^{\text {'push' }}$

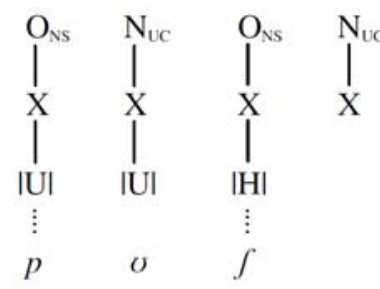

The final empty nucleus remains silent in accordance with the positive setting of the final-emptynucleus parameter (Harris 1994: 162, cf. Kaye 1995) in English. When this word undergoes regular plural formation, the suffix $-z<-(\mathrm{e}) \mathrm{s}>$ is added to the end of the word. Since this produces an impossible sequence of sibilants $s z$, it is traditionally assumed that the epenthesis of a vowel breaks up the sequence in accordance with the OCP, which bans two succesive sibilants. The epenthetic vowel is typically a (sometimes $\dot{i}$, depending on the accent). In the element-based framework, the epenthetic vowel is considered to be the phonetic realization of an empty nucleus which is flanked by two sibilants. Under this account, $\partial$ is not inserted: its phonological shape (empty nucleus) is already part of the lexical structure.

(6)

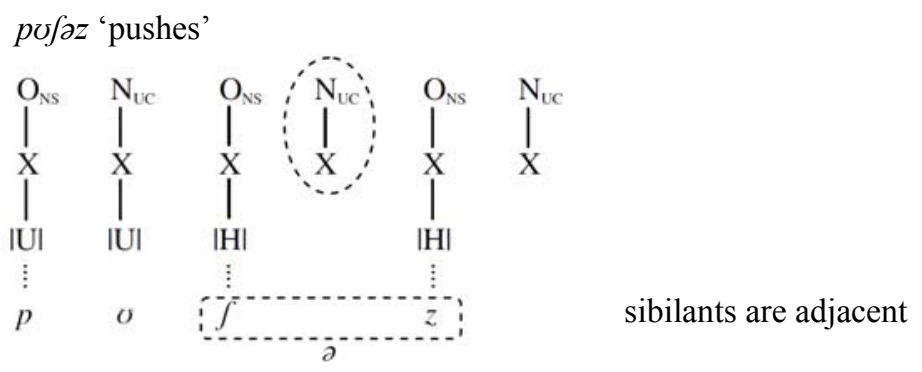

Vowel insertion in the nativization of loanwords also tells us which vowel is the default vowel in a given system, because this vowel is typically regarded as the phonetic manifestation of an empty nucleus. In English, for example, $\partial$ is again inserted before word-initial NC sequences (which are impossible in English) when they appear word-initially in the source language, as shown below.

\begin{tabular}{|c|c|}
\hline \multicolumn{2}{|c|}{ Borrowings with initial NC } \\
\hline Mpumalanga & әт, pu:mə 'lceygə \\
\hline mbeki & om beki \\
\hline Ndola & on 'davla \\
\hline nguni & әๆ'gu:ni \\
\hline Nkomo & оn 'kәбтаб \\
\hline
\end{tabular}

The epenthetic vowel used to break up impossible sequences differs from language to language: in Cilungu it is $\dot{i}$ (Bickmore 2007) and in Japanese $u$ (Nasukawa 2004, 2005, 2010). The following examples are from Japanese. 
(8)

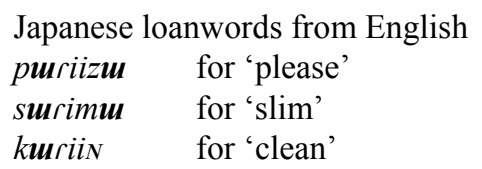

Interestingly, this type of epenthetic vowel cross-linguistically seems to be one of these central vowels $\partial, \dot{t}$, or $u$.

In the literature on Element Theory (ET: Harris \& Lindsey 1995, 2000; Harris 1994, 2005; Backley 2011) and Government Phonology (GP: Kaye, Lowenstamm \& Vergnaud 1990; Charette 1991; Harris 1994; Harris \& Gussmann 1998; Nasukawa 2004, 2005, 2010) it is assumed that the quality of the central vowel for any given language is made simply on the basis of parametric choice. Thus, no explicit explanation is given for why these vowels in particular are associated with the featureless nucleus.

\section{$4 \quad \mid$ A I U $\mid$ as the head of the nuclear expression}

In order to account for the parametric choice in non-arbitrary terms, I propose that the nucleus itself is one of the three vowel elements $|\mathrm{A}||\mathrm{I}|$ and $|\mathrm{U}|$. Given this, one of them determines the quality of a 'featureless' nucleus: as an acoustically weak form, $|\mathrm{A}|$ is phonetically realized as $\partial$ in English, $|\mathrm{I}|$ as $\dot{i}$ in Cilungu and $|\mathrm{U}|$ as $u$ in Japanese. In such cases, I assume that $|\mathrm{A}|,|\mathrm{I}|$ or $|\mathrm{U}|$ is the head of the nuclear expression in English, Cilungu and Japanese respectively. Under this view, we can explain why the central vowel is chosen from only three possibilities, rather than five or six. On this basis, the empty nucleus is replaced by the following three types of X-bar structure.

a. empty $\mathrm{N}_{U C}$

b. $\partial$<smiles>N#[W]N</smiles><smiles>[AlH2][AlH2]</smiles>

c. $i$<smiles>[Al]=[Al][Al-]</smiles>

d. $u$<smiles>[Al][Al]</smiles>

I assume that if a given expression is organized by only a single element, for example, $|\mathrm{A}|$, then, it is phonetically realized as $\partial$ as in (9b). This is the case in English. In the cases of Cilungu and Japanese, an empty nucleus in a traditional sense is replaced by only $|\mathrm{I}|$ and $|\mathrm{U}|$ respectively. Thus, depending on the choice of head element, languages are divided into three types in terms of the quality of the baseline: $|\mathrm{A}|-$ type (a), in $|\mathrm{I}|$-type $(i)$ and $|\mathrm{U}|$-type $(u)$.

Given the configuration (9b) for English, the structures of the three vowel patterns 'dIp', 'rUmp', 'mAss' in (2) are represented as follows.

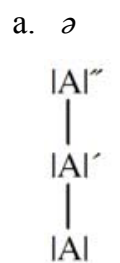

b. $i$<smiles>[Al][Al]1C=CC=[Al]1</smiles>

c. $u$

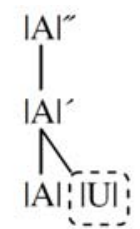

d. $a$<smiles>[Al][Al]1C=C[Al]C1</smiles>

When $|\mathrm{A}|$, the foundation of the structure, appears alone, it is phonetically realized as $\partial$, providing the baseline timbre for English. On the other hand, it phonetically manifests itself as a segment which exhibits the 'dip' pattern when the element $|\mathrm{I}|$ is taken as a complement. This is due to the fact that the acoustic pattern of $|\mathrm{I}|$ is superimposed onto this baseline resonance. The same interpretation is taken in the cases of (10c) and (10d): the $|\mathrm{A}|$-labelled set of $|\mathrm{A} \mathrm{U}|$ and the $|\mathrm{A}|$-labelled set of $|\mathrm{A} \mathrm{A}|$ are phonetically realized as $u$ 
and a respectively. Accordingly, the Comp in the above configuration contributes to the vocalic quality of a given melodic structure.

In the case of Japanese, for example, the head is $|\mathrm{U}|$, so that the structure that is formed by only the head $|\mathrm{U}|$ is phonetically realized as $z$ as in (11a). When the head $|\mathrm{U}|$ take $|\mathrm{I}|,|\mathrm{U}|$ and $|\mathrm{A}|$ in the Comp, then the acoustic signature of the baseline is masked by those elements and the overall structure phonetically manifests itself as $i, u(u)$ and $a$ respectively.

a. $w$<smiles>[AlH2]Br</smiles>

b. $i$<smiles>[Al]C1C=CC=[Al]1</smiles>

c. $u(u)$

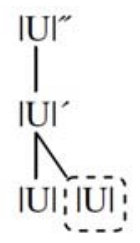

d. $a$<smiles>[Al]C1C=CC=[Al]1</smiles>

Following other linguistic components and other domains in phonology, I assume that the head element can take an element as an argument in the Spec. Below I give examples from English using the element $|\mathrm{I}|$.<smiles>[AlH2][AlH2]</smiles>

b. $j i$<smiles>[AlH2][AlH2][AlH2]</smiles>

c. $j u$<smiles>[AlH2][AlH2][AlH2]</smiles>

d. ja

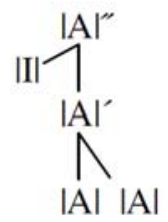

Like the widely-recognized syllable structure based on the X-bar schema, an item in the Spec is assumed to be phonetically interpreted as a consonant. Given this, $|\mathrm{I}|$ in the Spec phonetically manifests itself as a palatal glide $j$, the consonantal persona of $|\mathrm{I}|$. (Likewise, if $|\mathrm{U}|$ occupies the Spec in place of $|\mathrm{I}|$, then this is phonetically realized as the labio-velar glide $w$.) So, the structure is interpreted as $j$ when $|\mathrm{A}|$ takes $|\mathrm{I}|$ only in the Spec as in (12a). On the other hand, when $|\mathrm{A}|$ takes one of three elements in the Comp, then the structure is realized as $j+a$ peripheral vowel: $j i, j u$ and $j a$ as in (12b), (12c) and (12d) respectively.

\section{Recursion in compound expressions}

This section now considers complex expressions for vowels such as $e$ and $o$ with the proposed configuration. As discussed in the ET and GP literature, those vowels are viewed as a compound of two elements: $e$ and $o$ are the realisation of $|\mathrm{A} \mathrm{I}|$ and $|\mathrm{A} \mathrm{U}|$ respectively, as given below.

\section{Representing e and $o$}
a. $e$
b. $o$
III
$N$
|U|
II |A |
$\overbrace{|\mathrm{UI}| \mathrm{A} \mid}$

In the configuration in (13a), $|\mathrm{I}|$ and $|\mathrm{A}|$ are asymmetrically concatenated to form a vocalic expression, where $|\mathrm{I}|$ is the head while $|\mathrm{A}|$ is its dependent (modifier) in the Comp. Since the head characterizes a given set to which it belongs (endocentric dependency), as illustrated above, the head $|\mathrm{I}|$ is considered to be projected onto the next level above: the $|\mathrm{I}|$-labelled set of $|\mathrm{I}|$ and $|\mathrm{A}|$. In the same way, as in (13b), the set of 
$|\mathrm{U}|$ and $|\mathrm{A}|$ which is interpreted as the mid back vowel $o$ is $|\mathrm{U}|$-labelled.

On the other hand, the reverse labelling yields $\varepsilon$ and $\rho$ as in (14a) and (14b) respectively.

$$
\begin{aligned}
& \text { Representing } \varepsilon \text { and } \supset \\
& \text { a. } \varepsilon \\
& \text { b. } 0
\end{aligned}
$$

The difference in phonetic manifestation is thus attributed to the labelling: the acoustic pattern of the (labelled) head element is more prominent than that of the (non-labelled) dependent in the resulting acoustic signature.

Given these structures for mid vowels, the palatal glide + mid vowels are represented as in (15), where all configurations in (13) and (14) appear in the Comp.

a. je

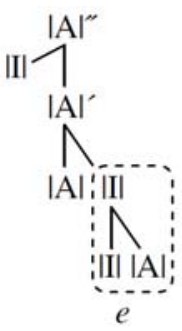

b. $j \varepsilon$<smiles>[AlH2][AlH2]</smiles><smiles>[AlH2]</smiles><smiles>[N]</smiles>
$|\mathrm{A}| \mathrm{I}|\mathrm{A}|$

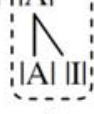

c. jo

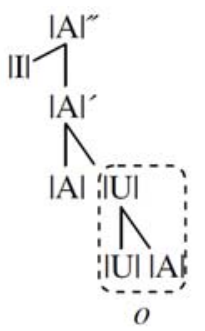

d. jo

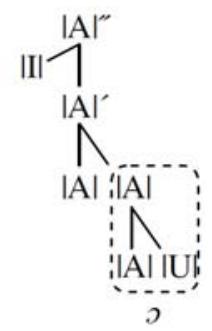

In the same manner, the Spec can have compound expressions, as exemplified in (16), where the $|\mathrm{U}|-$ labelled set $[|\mathrm{H}|[|\mathrm{U}||\mathrm{P}|]]$ and the $|\mathrm{I}|$-labelled set $[|\mathrm{I}||\mathrm{H}|]$ phonetically manifest themselves as the aspirated bilabial stop $p^{h}$ and the palato-alveolar fricative $\int$ respectively (For a detail discussion of consonantal representations, refer to Backley (2011)).

$$
p^{h} \delta f^{\circ} \text { push' }
$$

Note that this model assumes that $\mathrm{C}_{2}$ of $\mathrm{C}_{1} \mathrm{VC}_{2}$ (e.g., $\int$ in $p^{h} v \int$ 'push') is not part of the first $|\mathrm{A}|$-labelled configuration: $\mathrm{C}_{2}$ is in another $|\mathrm{A}|$-labelled set which is preceded by the set interpreted as $p^{h} \mho$. This representation for domain-final (morpheme-final) $\mathrm{Cs}$ is interpreted as a structure where an onset $\int$ is followed by a melodically empty nucleus in the tradition of GP and its offshoots. In the standard GP framework, a domain-final empty nucleus is phonetically suppressed in accordance with the positive setting of the final-empty-nucleus parameter. In (16), however, rather than an empty nucleus, the $|\mathrm{A}|$-labelled set with no Comp (which is phonetically realized as $\partial$ in English) remains silent in response to the positive setting of the final-empty-nucleus parameter. By contrast, as illustrated in (6), when the suffix $-z<-(\mathrm{e}) \mathrm{s}>$ is added to the end of the word under the regular plural formation, the $|\mathrm{A}|$-labelled set with no Comp becomes audible in the form of $a$ in order to avoid producing an impossible sequence of sibilants $s z$. This fulfills the OCP requirement that bans two succesive sibilants. 
It is apparent that the proposed element-based structures of melodic representation involve recursion which consists of embedding a constituent in another constituent of the same type. A typical example is as follows.

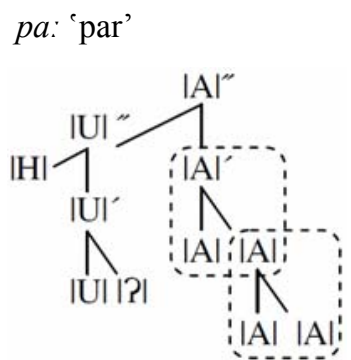

In (17), the sets enclosed in dotted lines are identical. The structure (17) consists of embedding a constituent in another constituent of the same type.

In disyllabic words such as in (18) where the ultimate head of the word domain is the element $|\mathrm{A}|$, we also observe recursion in terms of elemental composition.

(18)

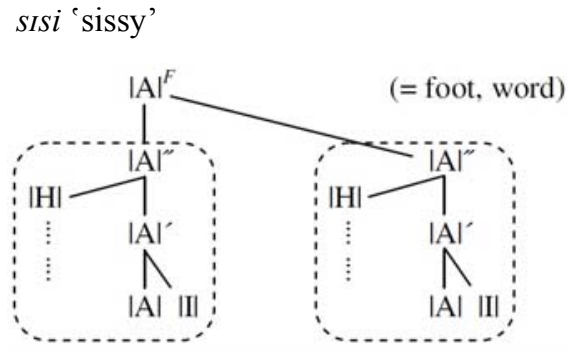

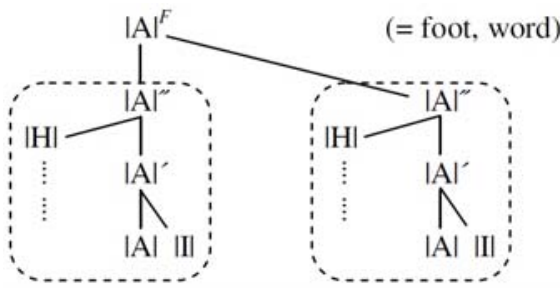

Thus, in the model which employs a concatenation-based form of melodic construction, we can ultimately dispense with constituents such as segment, onset, nucleus, rhyme, syllable and foot, all of which are generally assumed to be present at the intra-morphemic level. This leads to the proposal that elements, and not prosodic constituents, are the only variables relevant to the structural operations which describe phonological phenomena.

Based on the preceding arguments, the phonetic manifestation of element compositions (phrases) is determined by the intrinsic nature of elements and their head-dependency relations (labelling). This means that we have to admit recursion at least at a descriptive level. It may be possible to assume that morphosyntactic computation, which is observable, is a projection/reflection of phonological lexicalization, which is obscured by the sheer size of the structural composition.

\section{Concluding remarks}

At this point, let me consider whether syntax-like recursion exists in intra-morphemic phonology. As phonology is concerned with the well-formedness of sound structure, it is naturally assumed that one of the roles of phonology is to construct well-formed intra-morphemic structure. Coupled with the structural composition of elements, I assume that phonology is responsible for the sound aspects of lexicalization, which may correspond to structure-building in morpho-syntax, since recursion and the unlimited concatenation of elements both take place in the examples described above. In these element-based examples of melodic structure, the length of a morpheme (that is, the limit of recursive concatenation) is not constrained by phonology. The limits on recursive structure in the actual form of morphemes are imposed by performance factors such as memory, not by competence. 
As you may notice, the structural apporach I have proposed may be viewed as a phonological implementation of bare phrase structure. That is, this model reinterprets the notion of minimalism in phonology by opposing the string-based flat structure pursued by Scheer (2004), Neeleman \& van de Koot (2006), Samuels (2009) and others. Although there are representational differences, the present research concurs with those studies using a string-based flat structure for intra-morphemic phonology that there can be no intra-morphemic prosodic structure.

Finally, let me discuss some implications of adopting the structures proposed here. Within the framework developed by Hauser, Chomsky \& Fitch (2002), the existence of element-based recursive structure implies the possibility that phonology is placed in FLN rather than FLB if they maintain the view that the existence of recursive structure is a prerequisite for being placed in FLN. Within Pinker \& Jackendoff's framework, where phonology is in any case assumed to be unique to language (part of FLN), the existence of element-based recursive structure serves as evidence to support the recursion-only hypothesis of FLN which Pinker \& Jackedoff have denied. In either case, the existence of the proposed recursive structure suggests that intra-morphemic phonology is part of FLN.

\section{References}

Backley, Phillip. (2011). An Introduction to Element Theory. Edinburgh: Edinburgh University Press.

Backley, Phillip \& Kuniya Nasukawa. (2009). Representing labials and velars: a single 'dark' element. Phonological Studies, 12, 3-10.

Backley, Phillip \& Kuniya Nasukawa. (2010). Consonant-vowel unity in Element Theory. Phonological Studies, 13, $21-28$.

Bickmore, Lee S. (2007). Cilungu Phonology. Stanford: CSLI Publications.

Botma, Bert, Nancy C. Kula \& Kuniya Nasukawa. (2011). Features. In Nancy C. Kula, Bert Botma \& Kuniya Nasukawa (Eds.), Continuum Companion to Phonology (pp. 33-63). London: Continuum.

Charette, Monik. (1991). Conditions on Phonological Government. Cambridge: Cambridge University Press.

Harris, John. (1990). Segmental complexity and phonological government. Phonology, 7, 255-300.

Harris, John. (1994). English Sound Structure. Oxford: Blackwell.

Harris, John. (1997). Licensing Inheritance: an integrated theory of neutralisation. Phonology, 14, 315-370.

Harris, John. (2005). Vowel reduction as information loss. In Philip Carr, Jacques Durand \& Colin J. Ewen (Eds.), Headhood, Elements, Specification and Contrastivity: Phonological Papers in Honour of John Anderson (pp. 119-132), Amsterdam/Philadelphia: John Benjamins.

Harris, John \& Edmund Gussmann. (1998). Final codas: why the west was wrong. In Eugeniusz Cyran (Ed.), Structure and Interpretation in Phonology: Studies in Phonology (pp. 139-162), Lublin: Folium.

Harris, John \& Geoff Lindsey. (1995). The elements of phonological representation. In Jacques Durand \& Francis Katamba (Eds.), Frontiers of Phonology: Atoms, Structures, Derivations (pp. 34-79), Harlow, Essex: Longman.

Harris, John \& Geoff Lindsey. (2000). Vowel patterns in mind and sound. In Noel Burton-Roberts, Philip Carr \& Gerry Docherty (Eds.), Phonological Knowledge: Conceptual and Empirical Issues (pp. 185-205), Oxford: Oxford University Press.

Hauser, Marc D., Noam Chomsky \& W. Tecumseh Fitch. (2002). The faculty of language: what is it, who has it, and how did it evolve? Science, 298, 1569-1579.

Hulst, Harry van der. (2010). A note on recursion in phonology. In Harry van der Hulst (Ed.), Recursion and Human Language (pp. 301-341), Berlin/New York: Mouton de Gruyter.

Jakobson, Roman, Gunnar M. Fant \& Morris Halle. (1952). Preliminaries to Speech Analysis. Cambridge, MA: MIT Press.

Jakobson, Roman \& Morris Halle. (1956). Fundamentals of Language. The Hague: Mouton.

Kaye, Jonathan D. (1990). 'Coda' licensing. Phonology, 7, 301-330.

Kaye, Jonathan D. (1992). Do you believe in magic? The story of $s+\mathrm{C}$ sequences. SOAS Working Papers in Linguistics and Phonetics, 2, 293-314.

Kaye, Jonathan D. (1995). Derivation and interfaces. In Jacques Durand \& Francis Katamba (Eds.), Frontiers of Phonology: Atoms, Structures, Derivations (pp. 289-332), Harlow, Essex: Longman. 
Kaye, Jonathan D., Jean Lowenstamm \& Jean-Roger Vergnaud. (1990). Constituent structure and government in phonology. Phonology, 7, 193-232.

Nasukawa, Kuniya. (2004). Word-final consonants: arguments against a coda analysis. Proceedings of the 58th conference, Tohoku English Literary Society (pp. 47-53).

Nasukawa, Kuniya. (2005). A Unified Approach to Nasality and Voicing. Berlin/New York: Mouton de Gruyter.

Nasukawa, Kuniya. (2010). No consonant-final stems in Japanese verb morphology. Lingua, 120, 2336-2352.

Nasukawa, Kuniya. (2011). Representing phonology without precedence relations. English Linguistics, 28, 278-300.

Nasukawa, Kuniya. (2012). The segment in monostratal phonology. Paper presented at the CUNY Conference on the segment, CUNY Graduate Center, New York.

Nasukawa, Kuniya \& Phillip Backley. (2008). Affrication as a performance device. Phonological Studies, 11, 35-46.

Neeleman, Ad and J. van de Koot. (2006). On syntactic and phonological representations. Lingua, 116, 1524-1552.

Samuels, Bridget. (2009). The third factor in phonology. Biolinguistics, 3.2, 355-382.

Scheer, Tobias. (2004). A Lateral Theory of Phonology: What Is CVCV and Why Should It Be? Berlin/New York: Mouton de Gruyter. 